\title{
GAMIFYING AIRPORT EXPERIENCE USING AUGMENTED REALITY
}

\author{
by \\ Lead Author: Yalda Pashai-Fakhri \\ Co-author: Naveed Khan
}

Bachelor of Fine Arts, Ryerson University, School of Image Arts, 2011

\author{
An MRP \\ presented to Ryerson University \\ in partial fulfillment of the \\ requirements for the degree of \\ Master of Digital Media \\ in the Program of \\ Digital Media
}

Toronto, Ontario, Canada, 2019

(C) Yalda Pashai-Fakhri, 2019 


\section{AUTHOR'S DECLARATION FOR ELECTRONIC SUBMISSION OF A THESIS}

I hereby declare that I am the sole author of this thesis. This is a true copy of the thesis, including any required final revisions, as accepted by my examiners.

I authorize Ryerson University to lend this thesis to other institutions or individuals for the purpose of scholarly research.

I further authorize Ryerson University to reproduce this thesis by photocopying or by other means, in total or in part, at the request of other institutions or individuals for the purpose of scholarly research.

I understand that my dissertation may be made electronically available to the public. 


\title{
GAMIFYING AIRPORT EXPERIENCE USING AUGMENTED REALITY \\ Yalda Pashai-Fakhri \\ Master of Digital Media \\ Digital Media \\ Ryerson University, 2019
}

\begin{abstract}
Continuous advancements in aerospace technology have led to incredible growth in the airline industry in the past three decades [1]. However, such rapid growth coupled with tighter security restrictions and stricter global travel requirements has led to a burgeoning logistical issue of handling in-transit passengers at airports. Due to security wait times, delays, cancellations and layovers, passengers are spending more time waiting and transiting at airports. This time is often considered to be "lost time" by passengers, as there is no positive or meaningful experience associated with it.

This proposal utilizes augmented reality (AR) to gamify the airport environment in an attempt to reclaim this "lost time" for passengers. With the use of a personal mobile device, travelers can initiate a timed journey through the airport that guides them to points of interest where they can complete challenges to earn credits. These credits can then be used towards discount purchases at retailers
\end{abstract}


and restaurants in the airport, resulting in a more positive airport experience for travelers and an increase in revenue for businesses. 


\section{Acknowledgements}

"Give me six hours to chop down a tree and I will spend the first four sharpening the axe."

- Abraham Lincoln

I would like to express my sincerest gratitude to my academic supervisors, David M.

Hogue, Ph.D. UX Design Lead at Google, and Alex Ferworn Ph.D. director of MDM at Ryerson University, who pointed me in the right direction and gave me the freedom to make necessary changes to hone my research and skills. I would also like to thank my second reader, Professor Sumit Bhatia who patiently guided me through the entire thesis project. 


\section{Dedication}

To my parents, Shahla and Hassan, who moved oceans to give us a life of our choosing.

And to my husband, who provided me with the foundation I needed as I took on too much, tirelessly supported and believed in my potential.

I am forever in awe of your kindness. 


\section{Table of Contents}

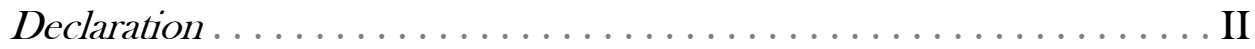

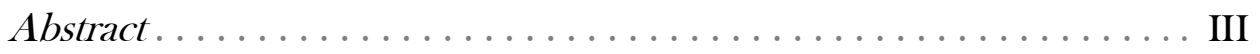

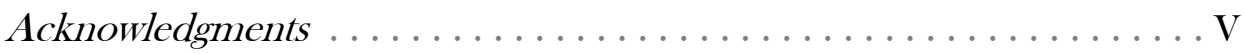

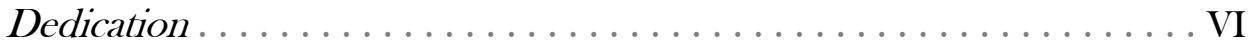

Table of Contents........................... VII

Chapter 1: Introduction 1

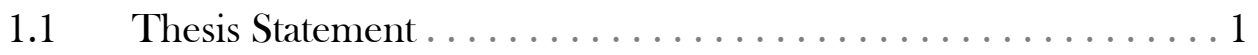

List of Figures

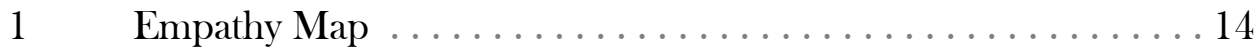

$2 \quad$ User Persona, ARport . . . . . . . . . . . . . . . . . 15

$3 \quad$ Application Architecture ....................... 16

$4 \quad$ User-Flow ........................... 18

$5 \quad$ Wireframes ............................. 19

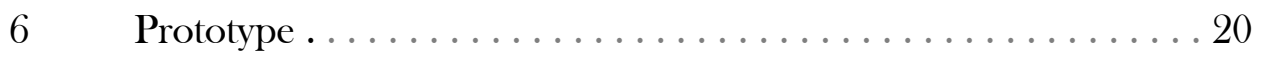

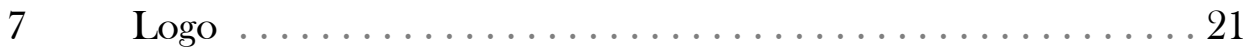

$8 \quad$ User Testing . . . . . . . . . . . . . . . . 22

$9 \quad$ User Testing . . . . . . . . . . . . . . . . 22 
Chapter 2: Background

$2.1 \quad$ Defining Experience $\ldots \ldots \ldots \ldots \ldots \ldots \ldots \ldots \ldots \ldots \ldots$

2.2 Defining Experience in an Airport Context . . . . . . . . . . . 4

$2.3 \quad$ Gamification $\ldots \ldots \ldots \ldots \ldots \ldots \ldots \ldots \ldots \ldots \ldots \ldots \ldots \ldots \ldots \ldots$

2.4 Gamification Elements .................... 7

$2.5 \quad$ Ethics of Gamification . . . . . . . . . . . . . . . 9

2.6 Gamifying the Airport .................... 10

$\begin{array}{ll}\text { Chapter 3: Methods and Materials } & 11\end{array}$

3.1 ARport: An Augmented Reality App for Airports . . . . . . . . . 11

3.2 Tools and Software ........................ 12

$\begin{array}{ll}\text { Chapter 4: Design Thinking } & 13\end{array}$

$4.1 \quad$ User Experience $\ldots \ldots \ldots \ldots \ldots \ldots \ldots \ldots \ldots \ldots \ldots \ldots$

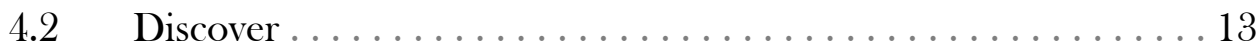

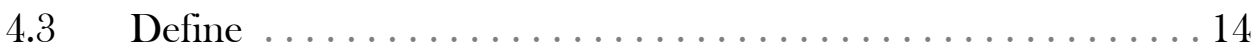

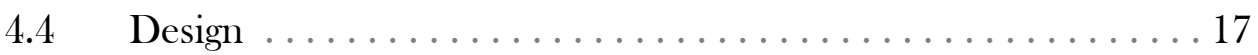

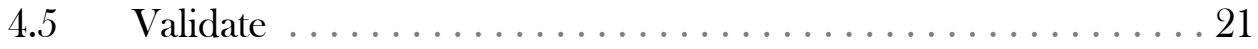


Chapter 5: Recommendations and Conclusion

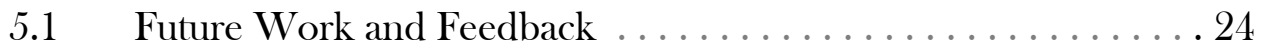

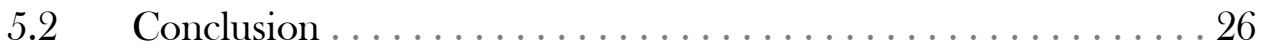

Bibliography

27 


\section{Chapter 1}

\section{Introduction}

\subsection{Thesis Statement}

Airports have always been dynamic hubs of activity. Aside from serving as transit nodes for travelers, they are subject to constant shifts in operational structure due to pressures of external factors such as trade regulations, international security measures, aerospace technology disruptions and more. In the past three decades, globalization in increased tourism has compounded the impacts of these external factors, resulting in significant difficulties in overall operational management of airports that negatively impacts the experience of travelers. In the past decade alone, the number of delayed and cancelled flights has increased dramatically, causing travelers to lose precious time while transiting and leading to increased customer dissatisfaction [2].

In order to resolve issues related to external factors, airport operators have

begun to deploy a range of technologies that allow them to better communicate and 
facilitate the movement of thousands of passengers a day. Automated baggage handling systems and digital boarding passes are just a couple ways airlines and airports are improving their operations [3]. Enhanced security requirements such as body scanners, combined with increased travel mass have resulted in more passengers with longer transit and wait times, thus little consideration has been given to improving the quality of the user experience for individual passengers. While many airports attempt to create a more pleasurable experience through seasonal programming, a wider range of retail, restaurants, and installations of art and architecture, they often fail to effectively communicate these opportunities to travelers, therefore the concept of "lost time" continues.

This major research project aims to examine the potential use of digital technology, specifically augmented reality on mobile platforms, in order to create experiences for travelers to actively engage with and explore airport programming in a fun, relevant and meaningful way. 


\section{Chapter 2}

\section{Background}

\subsection{Defining Experience}

While the meaning of the word "experience" may seem to be quite evident in our general usage, it is defined here for the purpose of understanding its significance as expressed when discussing "user experience”. An experience is a subjective, holistic, and personal interpretation, response, or reflection of an individual to stimuli in their environment, the perception of which is shaped by the individual's personal psychology as a culmination of their past experiences [4][5]. According to Volo [6] despite the inherently holistic nature of experiences, the way an individual perceives or reflects upon their experiences can be modified and conditioned by subsequent occurrences that capitalize on affecting touch points [7]. Contemporary literature emphasizes the significance of experience and claims it as a hedonic consumable composed of fantasies, feelings, and fun, which are the aspects customers seek in experiences. As observed in the service and marketing sector, experience is broken down into the three categories of process, 
phenomenon and outcome, all of which are influenced by different ontological and epistemological backgrounds, as well as interactions with technology, architecture, and service staff [8]. In the study of tourist experiences, the quantity of pleasure, satisfaction, value, and relationships are often used to determine the effects of experiential-outcome of an individual [9]. Physical, social, and product aspects all serve as influential factors in the interpretation of the knowledge, memory, perception, emotion, and self-identity phases of tourist experience. These factors shape the individual's understanding of self, thus becoming the motivating factors for future expectations [10].

\subsection{Defining Experience in an Airport Context}

Experience in an airport context can be examined with more constraints than general experience, as the environment within which the experience occurs serves as a vessel in which such experiences can be collected. When travelers enter into an airport, many claim to feel sensations of anxiety, excitement, stress, frustration or boredom. Many of these psychological states are motivated by previous experiences, either personal or learned [11]. These psychological states can be better understood through segmentation of traveler experiences based on the activities and interactions that they undergo as they traverse through the airport. These key activities can be defined as obligatory (e.g. security checks, customs 
declarations) or discretionary (ie. non-obligatory activities that are informed by the architecture and programming of an airport terminal) [12]. The perspectives of airport management, passengers, and the public also need to be considered, as the types of experiences each of these perspectives allows differ greatly in how they are assessed. Airport management often considers experience from an objective viewpoint and determines performance through measurement of numerical metrics, whereas the traveler's perspective is always more subjective and defined by personal expectations. Consolidating the viewpoint of all travelers creates the public perspective, which represents the collective traveler experience, and is typically collected through surveys or social media channels [13]. By bringing together both the psychological states and perspectives of travelers, airports can create positive experiences by applying culture, engagement, and a sense of place in order to facilitate the airport as an environment that is pleasurable as a destination [14].

\subsection{Gamification}

The past decade has seen a significant push for designers to focus on principles of User Experience (UX) and Human Centred Design (HCD) in all facets of a user's interaction with and experience of a product, system, or environment [15]. User experience has become vital for the success of online commercial activity, social media platforms, and mobile applications, leading designers to apply new concepts of technology and engagement. 
One concept that has seen considerable success in the past several years is the application of game mechanics or gamification of systems. Bakker and Demerouti [16] define gamification as "applying the mechanics of gaming to nongame activities to change people's behavior. When used in a business context, gamification is the process of integrating game dynamics (and new game mechanics) into a website, business service, online community, or marketing campaign in order to drive participation and engagement". Gamification borrows elements from video games and uses them in non-game contexts. It encompasses playful design and game theory within a business context in order to motivate user engagement and enhance user experience [17][18]. Through gamification, companies have the potential to foster more user engagement by providing opportunities for productive and valuable experiences rather than entertainment consumption, users can have more of an active experience via $\mathrm{AR}$ rather passive experiences; this also adds value to businesses through increased marketing that can be personalized and targeted [19].

In order to gain traction, capture users, and retain customers, businesses need to focus on creating innovative experiences on all platforms that lead to better perceived benefits for the users, higher engagement across demographics, and increased value and equity for the brand. Gamification allows businesses to provide benefits and value to users. Commercial giants such as McDonald's, Nike, Pepsi, and Samsung have all applied gamification in their marketing campaigns in the past 
several years with great success [20]. Online platforms such as Facebook, Twitter, and eBay have also added elements of gaming to their websites, such as the immensely popular FarmVille, in order to increase user engagement [21]. Social media and networking platforms, particularly, have found great success with gamification due to the inherent desire for people to want to play together, fostering closer relationships, exhibiting "viral behaviour", and leading to increases in new adopters [22]. Gamification can be used to drive new growth and interaction on existing platforms by rejuvenating the experience, connect to other platforms in meaningful ways, and also collect useful data on user engagement that can then be used by companies to further improve their services.

Gamification of e-businesses has opened up opportunities for new revenue streams by offering built-in reward mechanisms. By creating incentives for users to play, businesses can increase their customer footprint and retention.

\subsection{Gamification Elements}

The concept of gamification has seen significant application in the past decade, with greater clarity being found in the game mechanics, dynamic and aesthetic elements based on the game design theory [23]. Game mechanics, such as achievements, levels, leaderboards, and challenges, are elements that have been widely deployed with considerable success on traditional gaming platforms, rooting 
from theories on behaviorism and motivation drives to produce desired actions in the target user. Many of these elements have found their way into mobile applications and websites as a way to enhance user experience and retention [24][25]. Dynamics refers to the interaction and feedback behaviour of mechanics acting on player inputs and outputs over time, which can be used to qualify certain mechanics. Aesthetics refers to the desired emotional responses of players while interacting with the game application [24].

The challenge, then, lies in ensuring that a gamified application can successfully stimulate and motivate an enjoyable experience for the player. Therefore, the goals, objectives, and rules of the game need to be clear and explicit in structuring the challenges in the application, while also ensuring that challenges are neither too easy nor too difficult for maintaining players' motivation and creating an accessible environment for players of all levels [25]. Positive feedback via text, audio, graphics, or animations can help keep players motivated as they discover their successes or failures. Finally, to ensure that players remain satisfied and engaged while progressing through the game, there should also be scalable levels of difficulty to ensure that players are challenged according to their skill level and that the rewards they receive are representative of their efforts [26]. 


\subsection{Ethics of Gamification}

As gamification is often built around a system of engagement that directly affects or influences a user's behaviour, the ethics or moral philosophy of gamification needs to be addressed as a key component of the design process. Designers aim to persuade through a framework that they create; therefore, they should espouse a moral obligation to ensure that they carefully assess the impacts or consequences of their designs. Strategies to effectively determine how the gamification of a system or environment need to be established in the initial stages of the project. Furthermore, the businesses that stand to benefit from user participation in gamified environments should also be obligated to how the gamified system is affecting users, and whether or not the main beneficiary is the user or the business who profits from it. As stated by Chiel Versteeg, "the morality of the persuasive system can be evaluated by examining the possible consequences, the methods employed, motivations of designers and impact on moral character of the stakeholders" [28]. Over the past decade, users have become more aware and cautious of the manipulation of their behavior through entertainment and media, and have exhibited hostility towards systems that seek to influence their patterns and habits with little regard for their well-being in order to directly benefit

businesses. Designers and business leaders have a heavy role to play in the potential 
misuse of user behavior, protection of user data, and remaining true to the principles of human-centered design.

\subsection{Gamifying the Airport}

In the case of airports, a successful and cohesive gamified application should enhance both the travelers' experience and operations for the airport's services. On top of having access to a gamified platform, users should also be able to receive personalized information details regarding their travel itinerary. The platform should also offer opportunities for navigation and indoor mapping of points of interest within airports, as well as locations of retailers and restaurants.

Data gathered through the platform could provide a clearer insight on users' needs and requirements [27]. 


\section{Chapter 3}

\section{Methods and Materials}

\subsection{ARport: An Augmented Reality App for Airports}

ARport is an augmented reality game designed for airports, focusing on engaging travelers in a scavenger hunt style experience that takes them around the airport to points of interest. In order to maximize user engagement and encourage participation, game mechanics such as point systems, badges, and rewards can be offered. These game elements can then be transformed to have economic value and exchanged as a currency at airport businesses. The involvement of users with the gamified application could perhaps lead to increased personalization, which would optimize their airport experience by providing essential and specific information customized to their needs, ultimately ensuring that passengers stay informed while mobile, reduce time lost due to wayward navigation or idling in lounges, and have increased access to available services of the airport. 


\subsection{Tools and Software}

The prototype of ARport was built upon testing possible applications in Terminal 1 at Toronto Pearson International Airport. Two existing art installations, Tilted Sphere by Richard Serra and Flight Song by Robert Charles Coyle, were selected as cultural and artistic points of interest upon which AR elements could be superimposed. Using these installations as a starting point allowed for the creation of a simple challenge that involves solving clues that guide the player to an installation where they complete an AR game, collect rewards for their efforts, and solve the next clue to continue the game.

Adobe XD was used to create a wireframe and prototype for the app interface, and Unity with Vuforia was used to generate the AR elements that would simulate the user experience. The app was presented to users within a room that was furnished to appear similar to an airport environment and a scaled replica of Flight Song was fabricated to simulate user interaction as it might occur in Terminal 1 at Toronto Pearson International Airport. 


\section{Chapter 4}

\section{Design Thinking}

\subsection{User Experience}

ARport was created using the Design Thinking method as the main structure of the process, and the primary methods used are Stanford Design Thinking and Google Design Sprint. These human-centered design steps are categorized in phases, starting with discover and empathize, define and ideate, design and prototype and finally test and validate.

\subsection{Discover}

One of the many essentials of a good design requires two very important characteristics: discoverability and understanding of the problem and the user [29]. A designer seeks to understand the users needs, problems, and goals, while the product solution or service needs to incorporate discoverability with content, interaction, relevancy and ability to find meaning in the product or service. An anonymous quantitative survey of 84 participants was conducted and a problem was 
discovered, which the majority of people had an issue with, which was airport security, boredom and the experience of being in an airport. This is a key insight into what frustrates travelers before their initial flight departure. In order to feel and better understand the user's point of view, an empathy map was created. See below:

\section{EMPATHY MAP: AIRPORT AR Game}

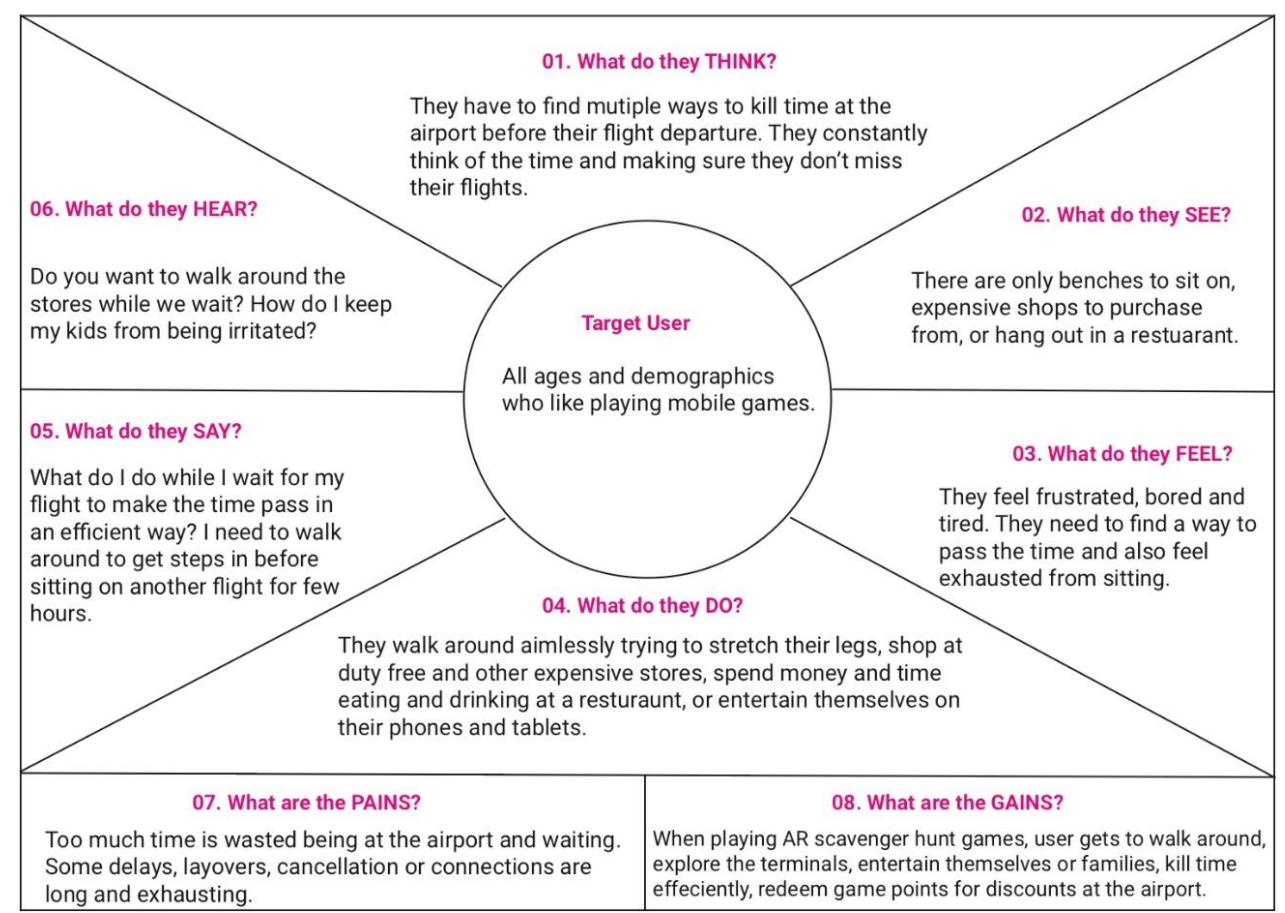

Figure 1: Empathy Map, ARport.

\subsection{Define}

This allowed us to ask how might we create a service where travelers can use their time at the airports more efficiently, which moved the project to the next 
phase in defining the problem statement. In order to understand and discover our users we must learn about the human mind and behavior. Donald Norman states that “... things are designed to be used by people, and without a deep understanding of people, the designs are apt to be faulty, difficult to use, difficult to understand." [29]. A user persona's value is in the specificity of the user's problem(s), representing the ideal target user and giving us insights into what an active user's attitudes and frustrations are. This gives ways to creating a hypothesis and a potential solution. Below is a fictional character created in this user-persona:

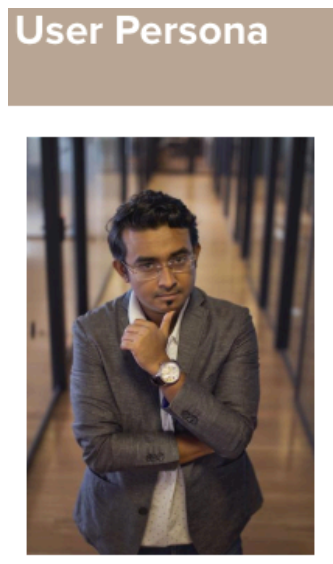

\section{Harv Ahmed}

Age: 42

Work: Senior Financial Advisor

Family: Married, 2 Kids

Location: Toronto, Canada

Personality: Introverted, family

oriented, travels frequently for

pleasure and business

\section{Systematic \\ World Traveler \\ Organized}

Goals

- Travel to 2 new places per year

- Visit family overseas once per year

- Show the adventure and beauty of traveling to his children

\section{Frustrations}

- With 2 young kids, he has a hard time keeping them entertained during long travel times such as in airports and on planes

- He always ends up paying more for airport food, drinks and duty free due to boredom

- Layovers between flights make his kids cranky and exhausted

- Long waits at airports make him anxious as he tries to maximize his vacation and not waste time

\section{Behaviour \& Attitude}

Whenever he has few minutes of free time, he plays video games. Harv has strong work ethics, and is ambitious to explore the world as much as he can, with the little time that he has. His family loves adventure and exploring new countries, and their' happiness is his priority.
Motivation

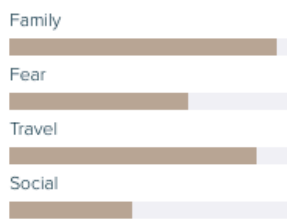

Brands

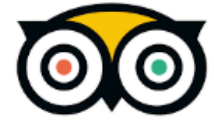
tripadvisor Expedia Toystus

Figure 2: User Persona, ARport. 
Once there is a target user in mind, then the structure of content strategy was created, this includes workflows of user movement and information architecture (IA) of the potential solution. This focuses more on the user's cognitive efforts and what the structural design would look like. Using the IA methods, app architecture and navigation model is created. See below:
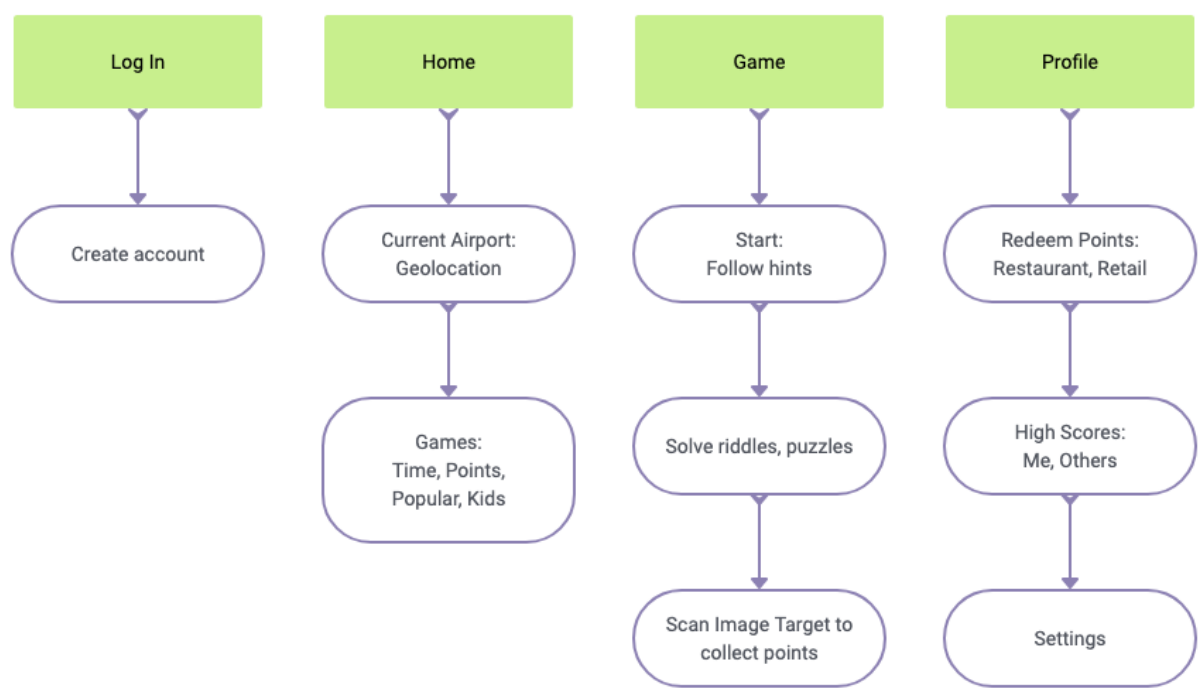

Figure 3: Application Architecture, ARport. 
This allowed us to have a clearer understanding of the user experience, ultimately simplifying the relationship between the solution and the user and facilitating the content and functionality of the service.

\subsection{Design}

In a highly digitalized world, apps can easily be buried in an oversaturated industry for many reasons, such as replications of similar services, inadequate advertising, partnerships and effective ways to draw attention. On the other hand, some apps can also be neglected or uninstalled if the flow of the design does not come naturally to the users. By creating a user-flow, we analyze the goals and the destination to where the user wants to reach and how to deliver that in the most efficient way possible regards to usefulness, added value and meaning, creating positive emotions and respectful and inclusive. In the case of ARport, below is the user-flow created to examine the actions of a user: 


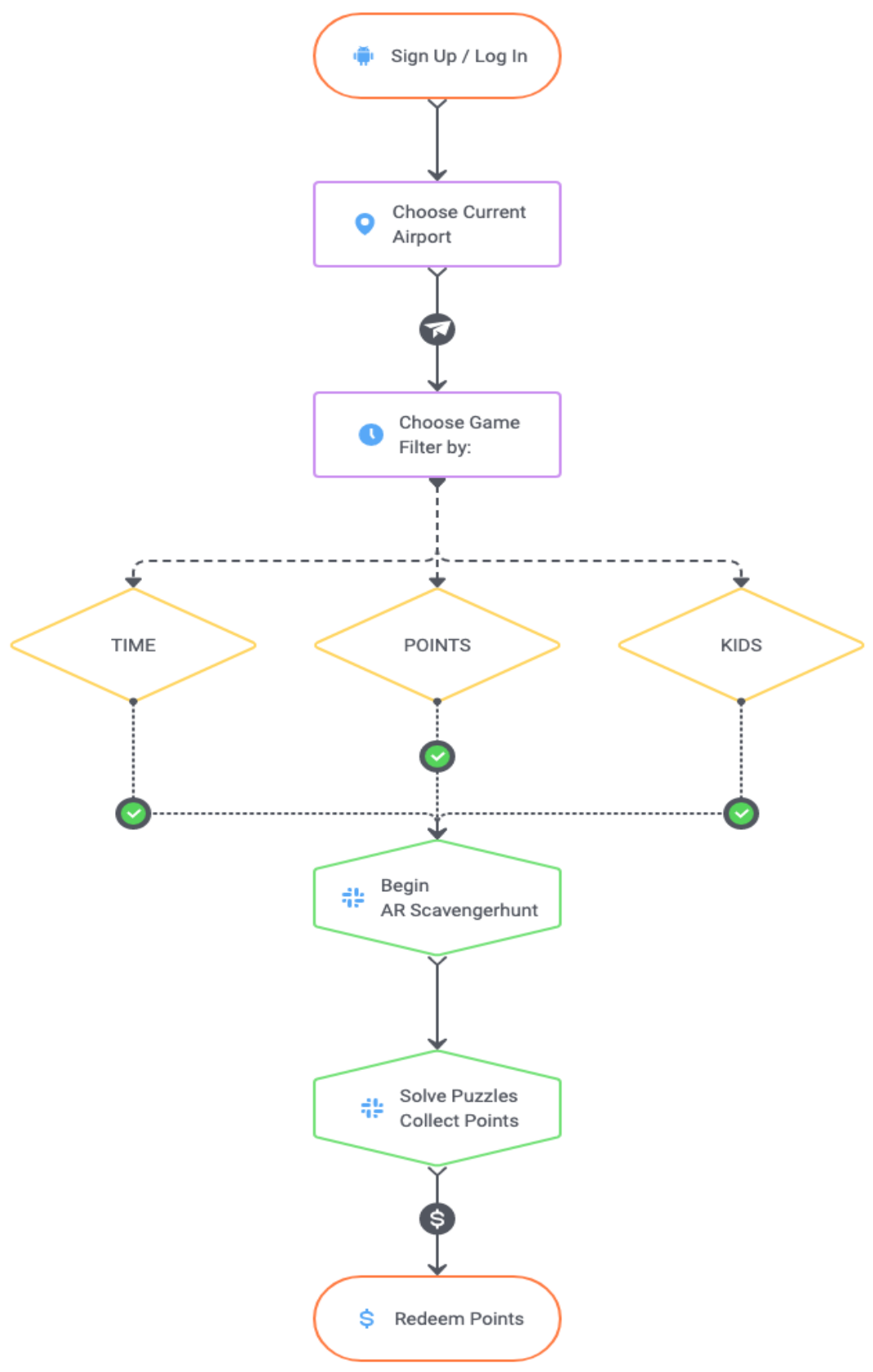

Figure 4: User-Flow, ARport. 
Once the user-flow and app architecture were created and analyzed, the next step that was followed was creating a blueprint of the design, called wireframes. This low fidelity of the skeleton of the app allows the team to fully grasp what the essential needs and flow of the app can look like. This process can involve various iterations, and below are a few screens of final wireframes:
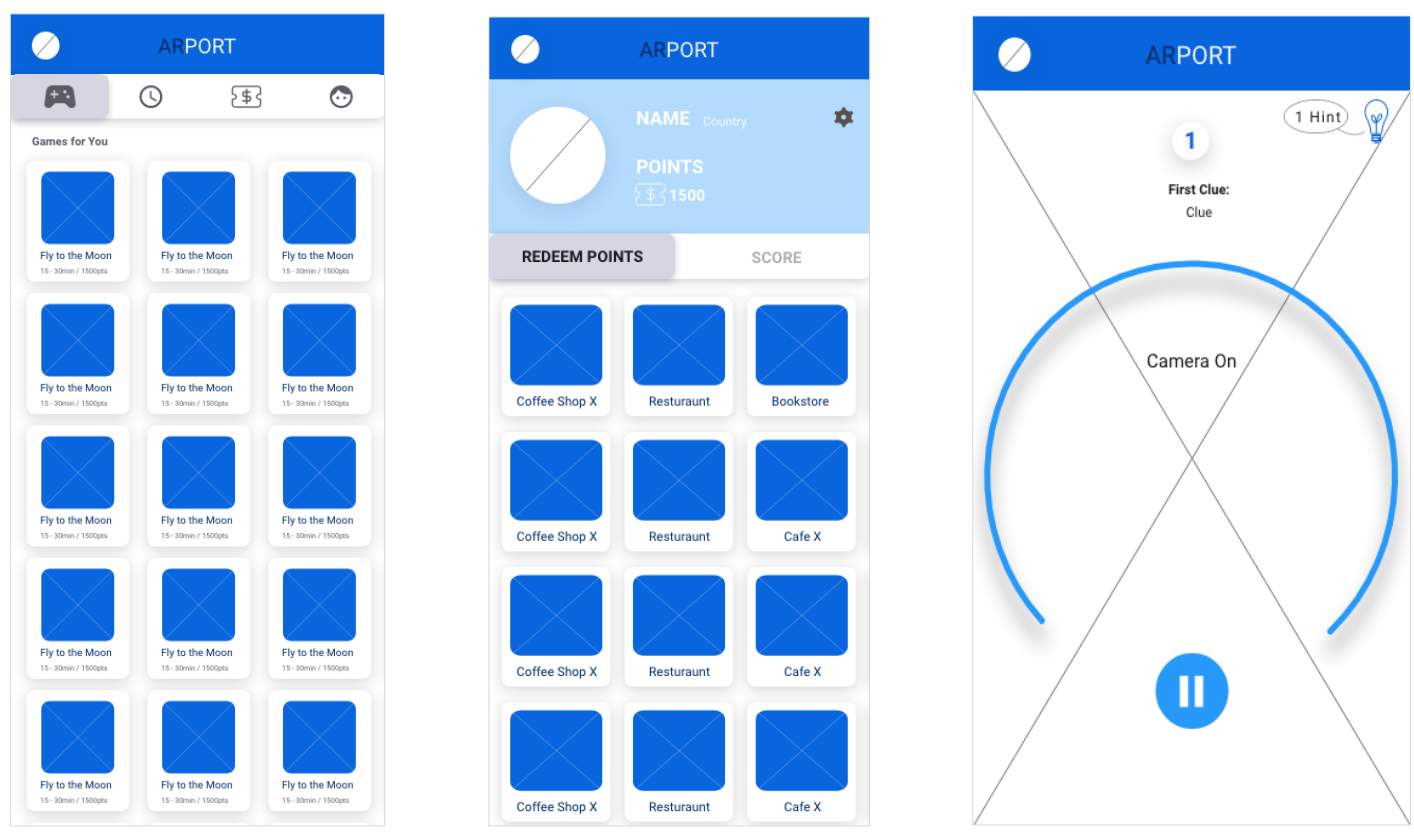

Figure 5: Wireframes, ARport.

Wireframes allow the concept and design to exist, whereas prototypes bring this concept to life. A high fidelity design is created by using the wireframes. In this step, it is crucial that the appropriate user interface (UI) is chosen, where human interaction with the device can come as naturally as possible. UI design is about 
managing user attention and focus, identity and brand, delivering effective content, eliciting emotions, and helping users interact with the product or service. In order to better understand the elements of an interface for ARport, Google’s Material Design was explored regarding layout, navigation, buttons, space and aligning. The goal is to make the affordances and signifiers of this app clear, giving cues for the users on how to interact with their app in order to achieve their goals. Below are screens of the final prototype after various iterations, as well as ARport logo:

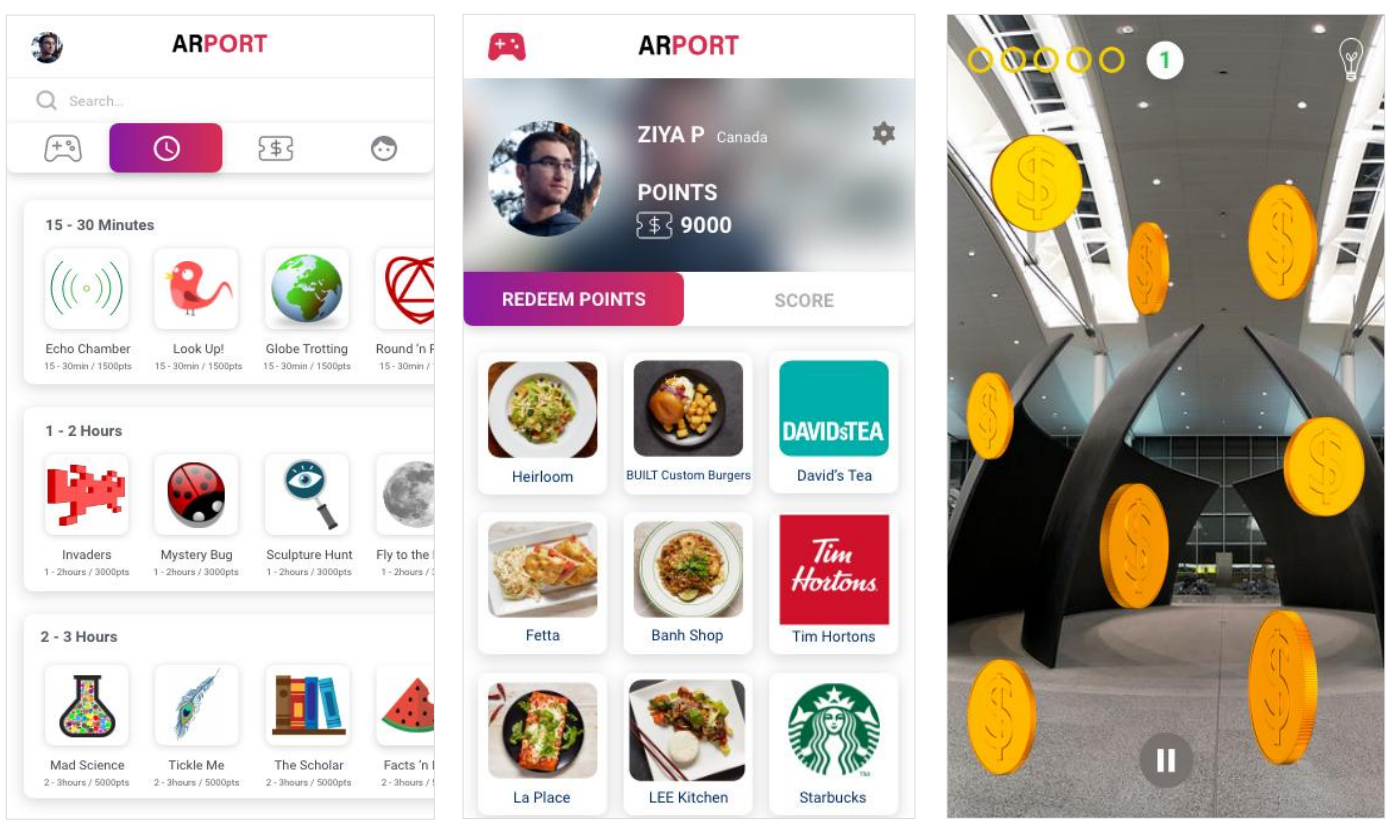

Figure 6: Prototype, ARport. 


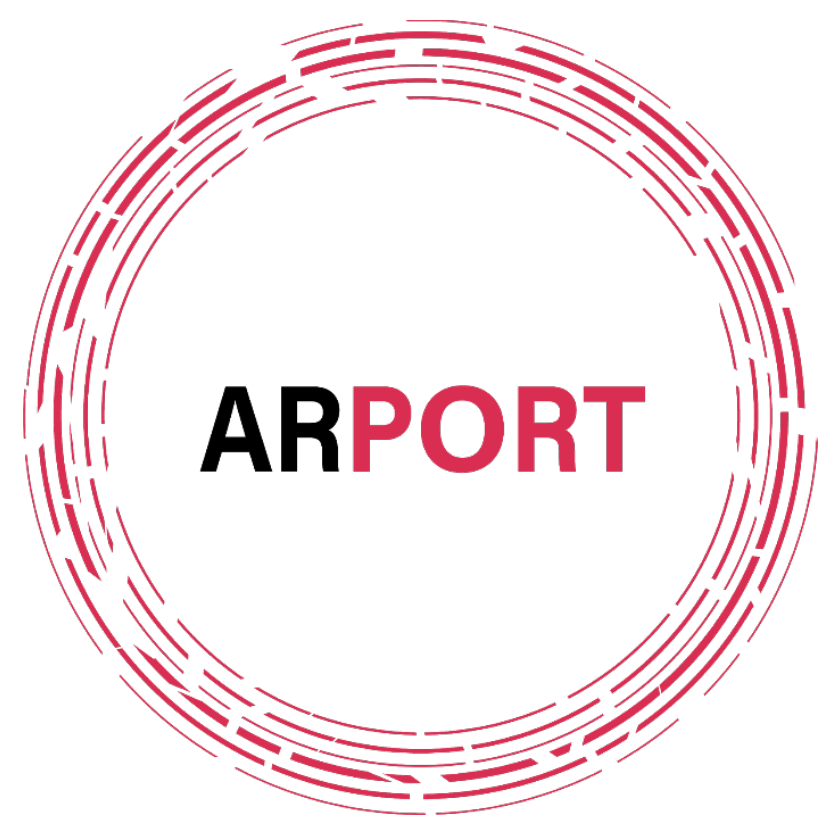

Figure 7: Logo, ARport.

\subsection{Validate}

When it comes to human-centered design, one of the many techniques used to validate an idea of a product or service, is through usability demonstrations, as these services are created for and used by humans, a user's voice, perspective, drives and needs are the ultimate reason why a design exists. Therefore, an inperson usability test was conducted for ARport, where 5 primary testers identified the most significant deficiencies with ARport. The feedback was analytically reviewed and all the common UI misunderstandings with the app were iterated and the prototype was updated. Graphs below show results on only two tasks on ease of use: 
How long did it take to figure out how to redeem points?

5 responses

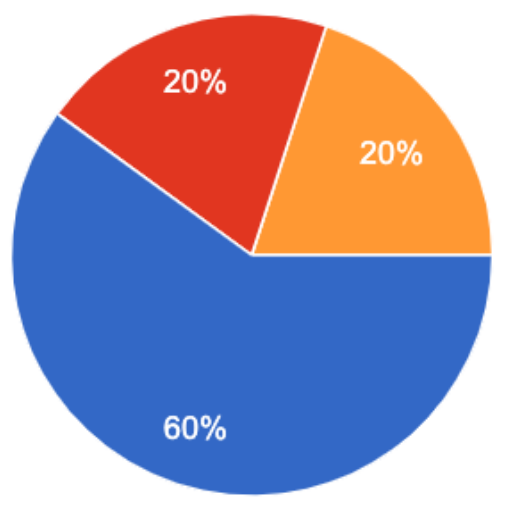

10 seconds

15 seconds

30 seconds +

Pick a game based on 30min time limit. How easy was this process?

5 responses

3

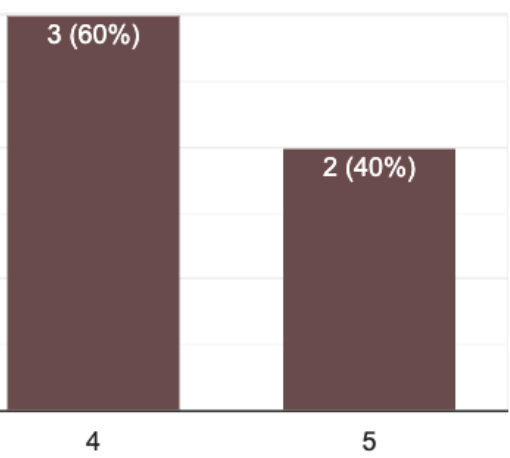

Figure 8 and 9: User Testing, ARport. 
Design is about communication and the act of empathy in understanding

human needs. Ultimately, this means that a good design has a deep knowledge of the person interacting with and communicating with this design. 


\section{Chapter 5}

\section{Recommendations and Conclusion}

\subsection{Future Work and Feedback}

Additional factors that would have value within the app aside from gaming would be integration of personalized flight information, indoor airport navigation using AR, and filtered options to cater to the needs of a more diverse demographic of travelers that responds to their specific travel frequencies, purposes, occupations, and age groups. Expanding ARport to international airports around the globe would however require a more significant research on the socio-cultural effects impacting user motivation based on their identity, such as on game play, role expectations, achievement incitement or use of points.

During the initial prototype testing in the fabricated airport environment indicated an interest for users to engage with AR game elements. These users showed minimal difficulty in operating the app, requesting assistance only when they were standing too close to the image target that they scanned in order to activate the AR game. There was a notable difference between the confidence that 
users exhibited, which was determined to be based on how much previous experience they had with AR in general. This suggests that more clarity is required in the instructions provided to users about pan and sweep distances when activating the AR game. This could be achieved through clever placement of AR components that suggestively guide users to move or rotate their positions, through discrete instructions provided to users prior to the activation of the game, or by promotional gameplay videos. Having said this, users in this environment were reacting to a simulated airport experience where there is no time urgency, travel anxiety, preparedness, findability and navigation, as there would be in a real airport experience. These circumstances in a real situation might change the user's level of reaction and willingness to ARport.

After playing the game, users reported that they would be likely to play games that helped them explore the airport environment as a means of making their time at airports more meaningful and fun. Users also commented on their interest in finding more active ways to spend their time at the airport while waiting for their flight, and there was a willingness of the majority of users to participate in the game with the promise of a tangible reward. As a part of building an experience, this form of a reward could manifest in multiple ways, either as discounts offered at participating partners and retailers at the airport, competitive leaderboards, location-based or seasonal competitions. The AR game that was presented to users 
was very simple, requiring users to collect coins on the screen by tapping on them. While the simplicity of the game allowed users with all ranges of experience to quickly understand and play the game, some users commented that the simplicity of the game reduced its level of engagement.

\subsection{Conclusion}

In order to create more engaging games, further research and focus will have to be placed on game design, puzzles, mechanics, dynamics or user interaction, and more stable AR environments. As the key focus of ARport is to

improve user experience in the airport environment, considerable energy will have to be spent on researching and developing a game with high fidelity and ubiquitous value. Initial conversations revealed that an AR gaming airport application could hold value for travelers to spend their idle time in a productive way by engaging with available programming and points of interest at the airport. Additional factors that would have value within the app aside from gaming would be integration of personalized flight information, indoor airport navigation using $\mathrm{AR}$, and filtered options to cater to the needs of a more diverse demographic of travelers that responds to their specific travel frequencies, purposes, occupations, and age groups. 


\section{Bibliography}

[1] International Air Transport Association. Facts \& Figures.

https://www.iata.org/pressroom/facts_figures/Pages/index.aspx

[2] Efthymiou, M et al. (2019). The Impact of Delays on Customers' Satisfaction: An Empirical Analysis of the British Airways On-Time Performance at Heathrow Airport. Journal of Aerospace Technology and Management, 11.

[3] Wattanacharoensil, W. et al. (2017). An analysis of the airport experience from an air traveler perspective. Journal of Hospitality and Tourism Management, 32, 124 135 .

[4] Genile, C., Spiller, N., \& Noci, G. (2007). How to Sustain the Customer Experience: An Overview of Experience Components that Co-create Value with the Customer. European Management Journal, 32(5), 395-410.

[5] Michael Morgan, M., Lugosi, P., \& Ritchie, B. (2010). The Dimensions of the Tourist Experience. In The tourism and leisure experience: consumer and managerial perspectives. Bristol, Buffalo: Channel View Publications.

[6] Volo, S. (2009). Conceptualizing experience: A tourist based approach. Journal of Hospitality Marketing \& Management, 18(2-3), 111-126.

[7] Holbrook, M. B., \& Hirschman, E. C. (1982). The experiential aspects of consumption: Consumer fantasies, feelings, and fun. Journal of Consumer Research, 9(2), 132-140.

[8] Edvardsson, B., Enquist, B., \& Johnston, R. (2005). Cocreating customer value through hyperreality in the prepurchase service experience. Journal of Service Research, $8(2), 149-161$. 
[9] Helkkula, A. (2011). Characterizing the concept of service experience. Journal of Service Management, 22(3), 367-389.

[10] Berry, L. L., Carbone, L. P., \& Haeckel, S. H. (2002). Managing the total customer experience. In MIT Sloan management review, spring, 85-89.

[11] Rowley, J., \& Slack, F. (1999). The retail experience in airport departure lounges: Reaching for timelessness and placelessness. International Marketing Review, 16(4/5), 363-376.

[12] Harrison, A., Popovic, V., \& Kraal, B. (2015). A new model for airport passenger segmentation. Journal of Vacation Marketing, 21(3), 237-250.

[13] Harrison, A., Popovic, V., Kraal, B. J., \& Kleinschmidt, T. (2012). Challenges in passenger terminal design: A conceptual model of passenger experience. In Proceedings of the design research society (DRS) 2012 conference, 344-356. Thailand: Department of Industrial Design, Faculty of Architecture, Chulalongkorn University.

[14] Wattanacharoensil, W., Schuckert, M., \& Graham, A. (2016). An airport experience framework from a tourism perspective. Transport Reviews, 36(3), 318-340.

[15] Partala, T., Saari, T., 2015. Understanding the most influential user experiences in successful and unsuccessful technology adoptions. Computers in Human Behavior, 53, 381-395.

[16] Bakker, A.B., Demerouti, E., 2007. The job demand-resource model: state of the art. Journal of Managerial Psychology, 22, 309-328.

[17] De-Marcos, L., Domínguez, A., Saenz-de-Navarrete, J., 2014. An empirical study comparing gamification and social networking on e-learning. Computers and Education. 75 (June), 82-91.

[18] Sailer, M., Hense, J.U., Mayr, S.K., Mandl, H., 2017. How gamification motivates: an experimental study of the effects of specific game design elements on psychological need satisfaction. Computers in Human Behavior, 69, 371-380.

[19] Yang, Y., Asaad, Y., Dwivedi, Y., 2017. Examining the impact of gamification on intention of engagement and brand attitude in the marketing context. Computers in Human Behavior, 73, 459-469. 
[20] Lau, G.T., Lee, S.H., 1999. Consumers' trust in a brand and the link to brand loyalty. Journal of Market: Focused Management, 4, 341-370.

[21] Insley, V., Nunan, D., 2014. Gamification and the online retail experience. International Journal of Retail and Distribution Management, 42 (5), 340-351.

[22] Domínguez, A., Saenz-de-Navarrete, J., de-Marcos, L., Fernández-Sanz, L., Pagés, C., Martínez-Herráiz, J., 2013. Gamifying learning experiences: practical implications and outcomes. Computers and Education, 63, 380-392.

[23] Kim, J. T., \& Lee, W. (2013). Dynamical model for gamification of learning (DMGL). Multimedia Tools and Applications. DOI: 10.1007/s11042-013-1612-8.

[24] Sicart, M. (2008). Defining game mechanics. The International Journal of Computer Game Research, 8(2).

[25] Deterding, S. (2014). The lens of intrinsic skill atoms: A method for gameful design. Retrieved from http://maint.ssrn.com/?abstract_id=2466871.

[26] Malone, T. W. (1981). Toward a theory of intrinsically motivating instruction. Cognitive Science, 4, 333-369.

[27] Toledo, T., \& Beinhaker, R. (2006). Evaluation of the potential benefits of advanced traveler information systems. Journal of Intelligent Transportation Systems, 10(4), 173-183.

[28] Versteeg, C. (2013). Ethics \& Gamification design. a Moral Framework for Taking Responsibility. Retrieved from https://dspace.library.uu.nl/handle/1874/281831.

[29] Norman, D. A. (2013). The Design of Everyday Things. New York: Basic Books. 